\title{
Interaction of Muc4 and ErbB2 in a transgenic mouse model of gallbladder carcinoma: Potential pathobiological implications
}

\author{
NAOKI MIYAHARA ${ }^{1}$, JUNICHI SHODA ${ }^{2}$, TORU KAWAMOTO ${ }^{3}$, HIROYASU ISHIDA ${ }^{4}$, TETSUYA UEDA ${ }^{5}$, \\ YOSHIHIRO AKIMOTO ${ }^{6}$, HAYATO KAWAKAMI $^{6}$ and TATSURO IRIMURA $^{7}$
}

${ }^{1}$ Department of Gastroenterology, Ushiku-Aiwa General Hospital, Ushiku, Ibaraki; ${ }^{2}$ Division of Medical Science, Faculty of Medicine, University of Tsukuba, Tsukuba-shi, Ibaraki; ${ }^{3}$ Department of Surgery, Institute of Gastroenterology, Tokyo Women's Medical University, Shinjuku-ku, Tokyo; ${ }^{4}$ Department of Gastroenterology, National Hospital Organization Mito Medical Center, Ibaraki-machi, Ibaraki; ${ }^{5}$ Department of Pharmaceutical Research, Mitsubishi Kagaku Bio-Clinical Laboratories, Inc., Itabashi-ku, Tokyo; ${ }^{6}$ Department of Anatomy, Kyorin University School of Medicine, Mitaka-shi, Tokyo; ${ }^{7}$ Institute for Medical Innovation, St. Luke's International Medical Center, Chuo-ku, Tokyo, Japan

Received May 27, 2014; Accepted June 30, 2014

DOI: $10.3892 / o r .2014 .3443$

\begin{abstract}
The molecular mechanism of gallbladder carcinogenesis and cancer growth remains unknown. BK5.erbB2 transgenic mice in which erbB2 is overexpressed and activated in the biliary epithelia develop adenocarcinoma of the gallbladder at a high incidence. Although it has been reported that erbB2 plays an important role in tumorigenesis, little is known about the involvement of its ligand(s). The expression level of Muc4, a potential functional ligand for erbB2, and its interaction with erbB2 in the gallbladder of BK5.erbB2 mice were determined. By immunohistochemistry and in situ hybridization, both Muc4 mRNA and protein levels were strongly expressed in the cancerous epithelia of gallbladder from BK5.erbB2 mice. Also, in the hyperplastic (precancerous) epithelia, the protein levels were modestly expressed. Immunostaining with Muc4 (ASGP2) Ab overlapped with that with erbB2 Ab in the apical membranous components of the cancerous epithelia, indicating the co-localization of Muc4 and erbB2. Immunoprecipitation experiments revealed an interaction between Muc4 and erbB2 in the gallbladders. The interaction was associated with the hyperphosphorylation of erbB2, MAPK and Akt, and also with the overexpression of cyclooxygenase-2. However, in other organs that overexpressed erbB2 (trachea, esophagus and forestomach), Muc4 was expressed in only trace or modest amounts, and erbB2 was not hyperphosphorylated. Collectively, Muc4 is upregulated and interacts with erbB2 in gallbladders from BK5.erbB2 mice. It
\end{abstract}

Correspondence to: Dr Junichi Shoda, Division of Medical Science, Faculty of Medicine, University of Tsukuba, 1-1-1 Tennodai, Tsukuba-shi, Ibaraki 305-8575, Japan

E-mail: shodaj@md.tsukuba.ac.jp

Key words: carcinogenesis, gallbladder, Muc4, erbB2, cell signaling is likely that Muc4 plays an important role during gallbladder carcinogenesis and/or cancer growth by potentiating erbB2 signaling.

\section{Introduction}

The incidence of biliary tract carcinoma has considerable geographic variations. High standardized mortality ratios of biliary tract carcinomas are found in cancer registries for Asian countries such as Japan and Thailand and for South American countries such as Chile, Peru and Colombia (1). Japan has one of the world's highest age-adjusted cancer death rates related to biliary tract carcinomas, and the rate appears to be steadily increasing, particularly for women (2).

Nearly two thirds of biliary tract carcinomas arise in the gallbladder, making it the most common biliary tract carcinoma. Gallbladder carcinoma has always been associated with a dismal overall prognosis $(3,4)$. This is essentially attributed to slow and asymptomatic growth of gallbladder carcinoma infiltrating surrounding structures, and the disease is therefore usually detected at an advanced stage with a high frequency of distant organ metastasis. Details of tumorigenesis as well as growth and progression of the disease are complex and not completely understood. Certain predisposing factors such as dietary habits (5), chronic cholecystitis (6) and the presence of an anomalous pancreaticobiliary junction (7) have been reported to be linked to the disease. Overexpression of erbB2, an erbB2 receptor tyrosine kinase family member, has been reported in a significant percentage of gallbladder carcinomas $(8,9)$.

BK5.erbB2 transgenic mice (BK5.erbB2 mice) that overexpress wild-type rat erbB2 under the control of the bovine keratin 5 (BK5) promoter have been generated (10) and found to develop adenocarcinoma of the gallbladder with high incidence (10). Alterations in erbB2 signaling have been implicated in neoplastic transformation in vitro (11) and in vivo $(12,13)$, and this model provides evidence that erbB2 signaling plays a role in gallbladder carcinogenesis. 
Several studies have shown the involvement of membrane mucins, including Muc4, in cell signaling (14-16). Muc4 is itself a heterodimeric glycoprotein composed of a mucin subunit, ascites sialoglycoprotein (ASGP1), and a transmembrane subunit, ASGP2. ASGP2 contains two epidermal growth factor (EGF) domains with conserved amino acid residues of active EGF-like growth factors, one of which reportedly acts as a ligand for erbB2 (16). Thus, Muc4 potentially acts as a novel transmembrane ligand for the tyrosine kinase erbB2, triggering specific phosphorylation of erbB2 (17). The expression level of Muc4 has previously been reported to be markedly upregulated in human gallbladder carcinomas $(18,19)$ and cholangiocarcinomas (20).

In the present study, we investigated the validity of the hypothesis that upregulation of Muc4 and its interaction with erbB2 in BK5.erbB2 mice are involved in the process of gallbladder carcinogenesis through modulation of phosphorylation of the receptor tyrosine kinase and subsequent erbB2 signaling for cell growth promotion.

\section{Materials and methods}

Generation and identification of transgenic mice. BK5.erbB2 mice were generated in the University of Texas, MD Anderson Cancer Center, Science Park Research Division (Smithville, TX, USA) as previously described (10). Transgenic animals were identified by PCR of DNA isolated from the tails of weanlings using oligonucleotides specific for the rabbit $\beta$-globulin cDNA as previously described (12). The organ specimens of BK5.erbB2 mice (gallbladder, trachea, esophagus and forestomach) were harvested in the University of Texas, MD Anderson Cancer Center, Science Park Research Division and supplied to the laboratories of Cancer Biology and Molecular Immunology, Graduate School of Pharmaceutical Sciences, University of Tokyo (Tokyo, Japan).

Real-time quantitative polymerase chain reaction. Steady-state mRNA levels were determined by real-time quantitative PCR using a GeneAmp 5700 Sequence Detection System (Applied Biosystems, Foster City, CA, USA). Primers and probes for mouse Muc4 (ASGP2) were designed using Primer Express (Applied Biosystems). In each experiment, PCR was carried out in triplicate. The PCR data were expressed relative to the amount of $r R N A$ present in each specimen and then averaged. The primers and probes were designed as follows: mouse Muc4 forward, 5'-GATGAGACAGAGTACCATGCAGATG-3' and reverse, 5'-GAACCGGCGTCTGAGAATAGA-3'; probe FAM5'-AACATCCCCAGAAGCGTGTACCCTGG-3'TAM.

In situ hybridization. Gallbladder tissues were immediately frozen in liquid nitrogen and stored at $-80^{\circ} \mathrm{C}$. Frozen sections of $8 \mu \mathrm{m}$ thickness were cut on a cryostat and thaw-mounted onto MAS-coated slides. The expression and localization of Muc4 (ASGP2) mRNA on the tissue sections were analyzed as previously described (21). The hybridization reaction was carried out at $52^{\circ} \mathrm{C}$ overnight. To detect Muc4 gene signals, the probe was synthesized using a Roche DIG RNA Labeling kit to utilize the following sequence: AAACCTCAAACCACCAC AACCACCGAGGTGACCACATCAACTCCTTCAGCCTC CTCACGTGACCAAATACAGACAGAGACAAGTTCTCA
AAGAACAATCTCTCCTGATGGAACAACCACCTCACA TGCTCCCAGTATCAGCAGCTCAGCTCCAAGTACAAC ACACATGTTAACCACAACATCCTCCACAGAAAGTAC CTCAGTAGACTCAGGACACACAACAGCAATAACAAC TCAAGGTTTAACACCTGCCACCGCACAAGTCTCACT GACACCTTCATCCCAGAATATGTCAACAGTGTCAACA CCCATCACCTCAACTCTTACTCAGAGACAACACACTG GAAGCAAGCAGACCAGCAGCA (GeneBank AF520422).

Immunoblot analysis. Whole tissue lysates and immunoprecipitates, which were prepared as previously described (12), were electrophoresed through 7-10\% SDS/polyacrylamide gels and transferred to polyvinylidene difluoride membranes. After blocking with $1 \%$ non-fat powdered milk in PBST $[0.05 \%$ Tween in phosphate-buffered saline (PBS)], the protein levels of Muc4 (ASGP2), erbB2, phosphorylated (p)-erbB2, MAPK, p-MAPK, Akt, p-Akt and Cox-2 were detected by incubating the membrane with the corresponding anti-Muc4 (ASGP2) antibody (Ab) (1:1,000; Zymed Laboratories, Inc. South San Francisco, CA, USA), anti-erbB Abs $(1: 1,000)$, anti-MAPK Abs (1:1,000), anti-Akt Abs (1:1,000) (all from Cell Signaling Technology, Beverly, MA, USA), anti-cyclooxygenase-2 (Cox-2) $(1: 1,000)$ or anti-microsomal prostaglandin $\mathrm{E}$ synthase-1 (mPGES-1) (1:500) (both from Cayman Chemical Company, Ann Arbor, MI, USA). Protein bands were visualized as previously described (12).

Immunohistochemical stainings. Immunohistochemistry was performed using formalin-fixed, paraffin-embedded tissue sections. Tissue sections were blocked with normal donkey serum and a Mouse-to-Mouse Detection system (Chemicon International, Temecula, CA, USA) and incubated with anti-Muc4 $\mathrm{Ab}$ overnight at $4^{\circ} \mathrm{C}$. After three washes with PBS, the tissue sections were incubated with the secondary FITC-conjugated, affinity-purified $F\left(a b^{\prime}\right) 2$ fragment of antimouse IgG (Jackson ImmunoResearch Laboratories, Inc., West Grove, PA, USA). The tissue sections were analyzed using a FluoroView Laser Confocal microscope (Olympus America, Melville, NY, USA). The localization of erbB2 and p-erbB2 was determined with their Abs (Cell Signaling Technology) by the same method as that used for the detection of Muc4.

Assay of tissue concentration of prostaglandin $E_{2}$. Frozen tissues were homogenized in an ice-cold buffer ( $\mathrm{pH} 8.4)$ and then stored at $-20^{\circ} \mathrm{C}$. Aliquots were assayed by a highly specific radioimmunoassay (anti-PGE $\mathrm{P}_{2}$ antibody; Amersham, London, UK) for $\mathrm{PGE}_{2}$ in duplicate and at two dilutions. The final results are expressed as $\mathrm{ng} \mathrm{PGE}_{2} / \mathrm{mg}$ protein.

Statistical analysis. Values are given as means \pm SE (standard error). Means of two groups were compared with the Mann-Whitney rank sum U test (two-tailed test), and multiple comparisons were performed by ANOVA. A P-value of $<0.05$ was considered to indicate a statistically significant difference.

\section{Results}

Expression status of Muc4 and ErbB2 in the gallbladder and other organs of BK5.ErbB2 transgenic mice. Immunoblot analysis of the gallbladder and other organ tissues showed 


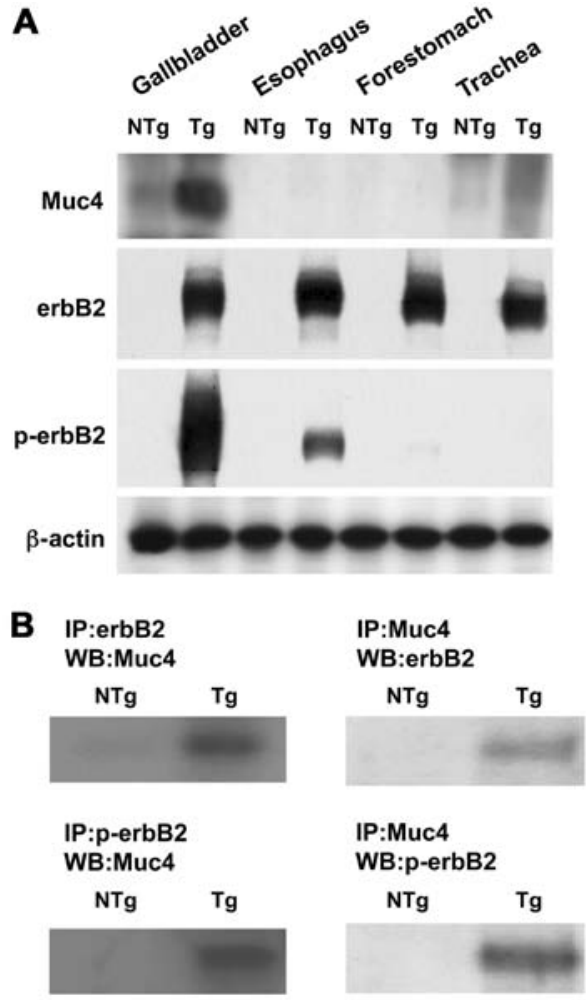

Figure 1. (A) Immunoblot analysis of Muc4 (ASGP2) and erbB2 status in the gallbladder and other organs (in which erbB2 is overexpressed under the control of the $K 5$ promoter) of non-transgenic (NTg) mice and the corresponding organs of BK5.erbB2 transgenic mice (3 months old). The whole cell lysate was analyzed by immunoblotting with antibodies (Abs) raised against Muc4 (ASGP2), erbB2 and p-erbB2. Protein was normalized to $\beta$-actin. (B) Lysates were immunoprecipitated with the $\mathrm{Ab}$ raised against erbB2 or that raised against p-erbB2 and then analyzed by immunoblotting with the Ab raised against Muc4. Alternatively, the lysates were also immunoprecipitated with the $\mathrm{Ab}$ raised against Muc4 and then analyzed by immunoblotting with the $\mathrm{Ab}$ raised against erbB2 or that raised against p-erbB2.

that, in BK5.erbB2 mice, Muc4 (ASGP2) protein was overexpressed in the gallbladder, whereas little or no Muc4 protein was found in the trachea, esophagus and forestomach, in each of which erbB2 is overexpressed (Fig. 1A). As expected, the expression levels of erbB2 protein were significantly increased in the gallbladder, trachea, esophagus and forestomach of BK5.erbB2 mice compared to the levels in NTg mice, whereas hyperphosphorylation of erbB2 was found only in the gallbladders (Fig. 1A).

Analysis of immunoprecipitation of gallbladder lysate with erbB2 followed by immunoblot with Muc4 revealed that coimmunoprecipitation of Muc4 with erbB2 as well as Muc4 with p-erbB2 was significantly increased ( $>30$-fold) in gallbladder carcinoma from BK5.erbB2 mice compared to gallbladders from NTg mice (Fig. 1B). These results were confirmed by analysis of immunoprecipitation with Muc4 followed by immunoblot with erbB2 (Fig. 1B).

Localizations of Muc4 and ErbB2 in the gallbladder of BK5.ErbB2 transgenic mice. The localizations of Muc4 (ASGP2) and erbB2 in the gallbladder of $8 \mathrm{NTg}$ mice and those of 10 BK5.erbB2 mice were determined by indirect immunofluorescence staining. Strong immunostaining with anti-Muc4 (ASGP2) Ab was observed in the cancerous epithelia as
Table I. Immunohistochemical expression of erbB2, phosphorylated erbB2 and Muc4 in gallbladders of non-transgenic and BK5.erbB2 Tg mice.

\begin{tabular}{llcc}
\hline & & \multicolumn{2}{c}{ BK5.erbB2 mice } \\
\cline { 3 - 4 } & $\begin{array}{c}\text { NTg mice } \\
(\mathrm{n}=8)\end{array}$ & $\begin{array}{c}\text { Hyperplasia } \\
(\mathrm{n}=8)\end{array}$ & $\begin{array}{c}\text { Carcinoma } \\
(\mathrm{n}=10)\end{array}$ \\
Gallbladders & $\mathrm{n}(\%)$ & $\mathrm{n}(\%)$ & $\mathrm{n}(\%)$ \\
\hline erbB2 & $4(50)$ & $8(100)$ & $10(100)$ \\
p-erbB2 & $0(0)$ & $2(20)$ & $10(100)^{\mathrm{a}}$ \\
Muc4 & $0(0)$ & $8(100)^{\mathrm{a}}$ & $10(100)^{\mathrm{a}}$ \\
\hline
\end{tabular}

${ }^{a} \mathrm{P}<0.01$, significantly different from NTg mice. NTg, non-transgenic.

being restricted predominantly to the apical membranous components of BK5.erbB2 mice (Fig. 2A). A modest degree of the immunostaining was also observed in the hyperplastic epithelia as being a precancerous lesion (22) (data not shown). However, no or only trace immunostaining was observed in the epithelia of NTg mice (Fig. 2A). Table I summarizes the results of immunohistochemistry of Muc4.

Immunostaining with anti-erbB2 Ab showed that a strong expression of erbB2 was observed in both the apical and basolateral membranous components of the cancerous epithelia of BK5.erbB2 mice (Fig. 2B). A modest degree of the immunostaining was also observed in the hyperplastic epithelia (data not shown). However, no or only a slight degree of the immunostaining was observed in the epithelia of NTg mice (data not shown). For the expression status of p-erbB2, the strong immunostaining with anti-p-erbB2 $\mathrm{Ab}$ was observed in the cancerous epithelia of BK5.erbB2 mice and a modest degree of the immunostaining was also observed in the hyperplastic epithelia of 2 BK5.erbB2 mice (data not shown). However, the immunostaining was not observed in any epithelia of NTg mice (data not shown). Table I summarizes the results of immunohistochemistry of erbB2 and p-erbB2.

Of note, the immunostaining with the Muc4 Ab overlapped (yellow, indicated by arrows) with those with the erbB2 Ab and with the p-erbB2 Ab in the apical membranous components of the cancerous epithelia, indicating the co-localization of Muc4 and erbB2/p-erbB2 (Fig. 2B and C).

Gene expression levels of Muc4 in the gallbladder and other organs of BK5.ErbB2 transgenic mice. The steady-state mRNA level of Muc4 (ASGP2) was significantly higher in the specimens of gallbladders of BK5.erbB2 mice $(108 \pm 7 \%$ of $r R N A$ mRNA, means $\pm \mathrm{SE} ; \mathrm{P}<0.01)$ than in those of NTg mice $(2 \pm 0.1 \%)$ (Fig. 3A). Analysis of in situ hybridization showed that Muc4 mRNA was expressed homogeneously in the epithelia but not in the stroma of specimens of gallbladder carcinoma tissues (Fig. 3B). Muc4 mRNA levels were significantly elevated in cancerous lesions of the gallbladder compared to non-cancerous lesions of the gallbladder from BK5.erbB2 mice and normal epithelia of gallbladder from NTg mice. The mRNA levels were not increased in the specimens of other organs, such as the trachea, esophagus and 


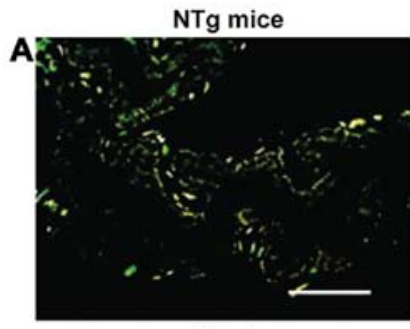

Muc4

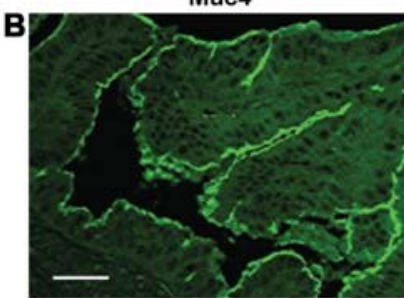

Muc4

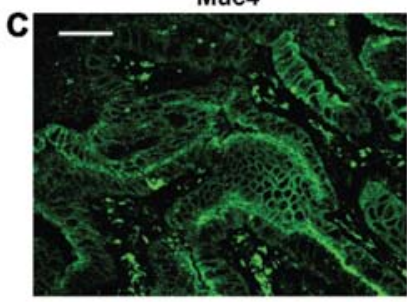

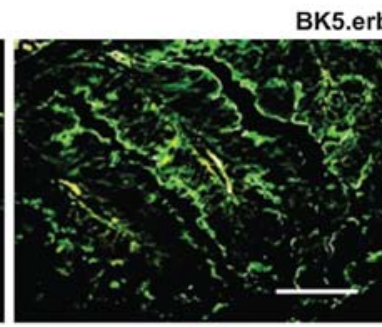

erbB2

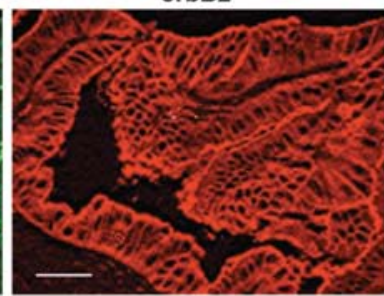

phospho-erbB2

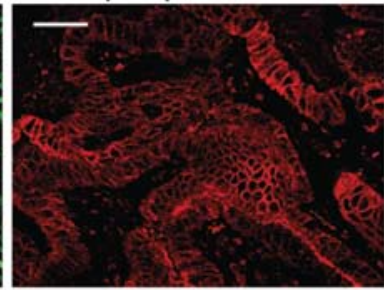

\section{5.erbB2 mice}

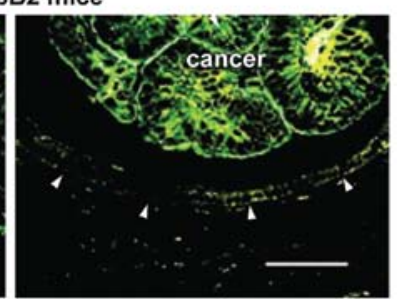

Merge

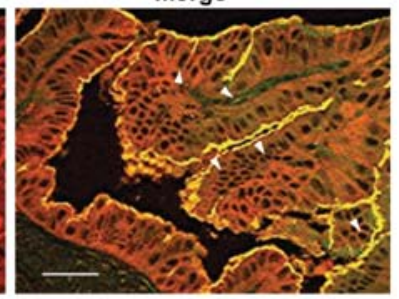

Merge

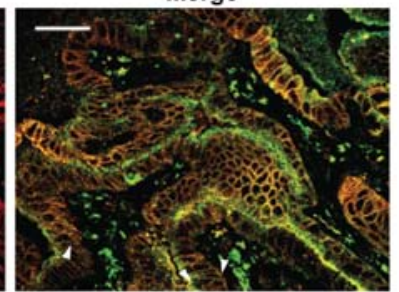

Figure 2. Expression levels and localizations of Muc4 (ASGP2), erbB2 and p-erbB2 in gallbladder tissue sections of non-transgenic (NTg) mice and BK5. erbB2 transgenic mice ( 3 months old). (A) Immunofluorescent stainings with anti-Muc4 (ASGP2) Ab. Immunostaining with the Muc4 Ab was observed in the cancerous epithelia (middle), but no or only trace amounts in the intact epithelia of gallbladders of NTg mice (left) and the non-cancerous epithelia of gallbladders of BK5.erbB2 transgenic mice (right, indicated by arrow heads). (B) Immunofluorescent staining with anti-Muc4 Ab (green) and that with anti-erbB2 Ab (red). (C) Immunofluorescent staining with anti-Muc4 Ab (green) and that with anti-p-erbB2 Ab (red). Immunostaining with the Muc4 Ab overlapped (yellow, indicated by arrows) with those with the erbB2 Ab and with the p-erbB2 Ab in the apical membranous components of the cancerous epithelia, indicating the co-localization of Muc4 and erbB2. Bars, $50 \mu \mathrm{m}$.
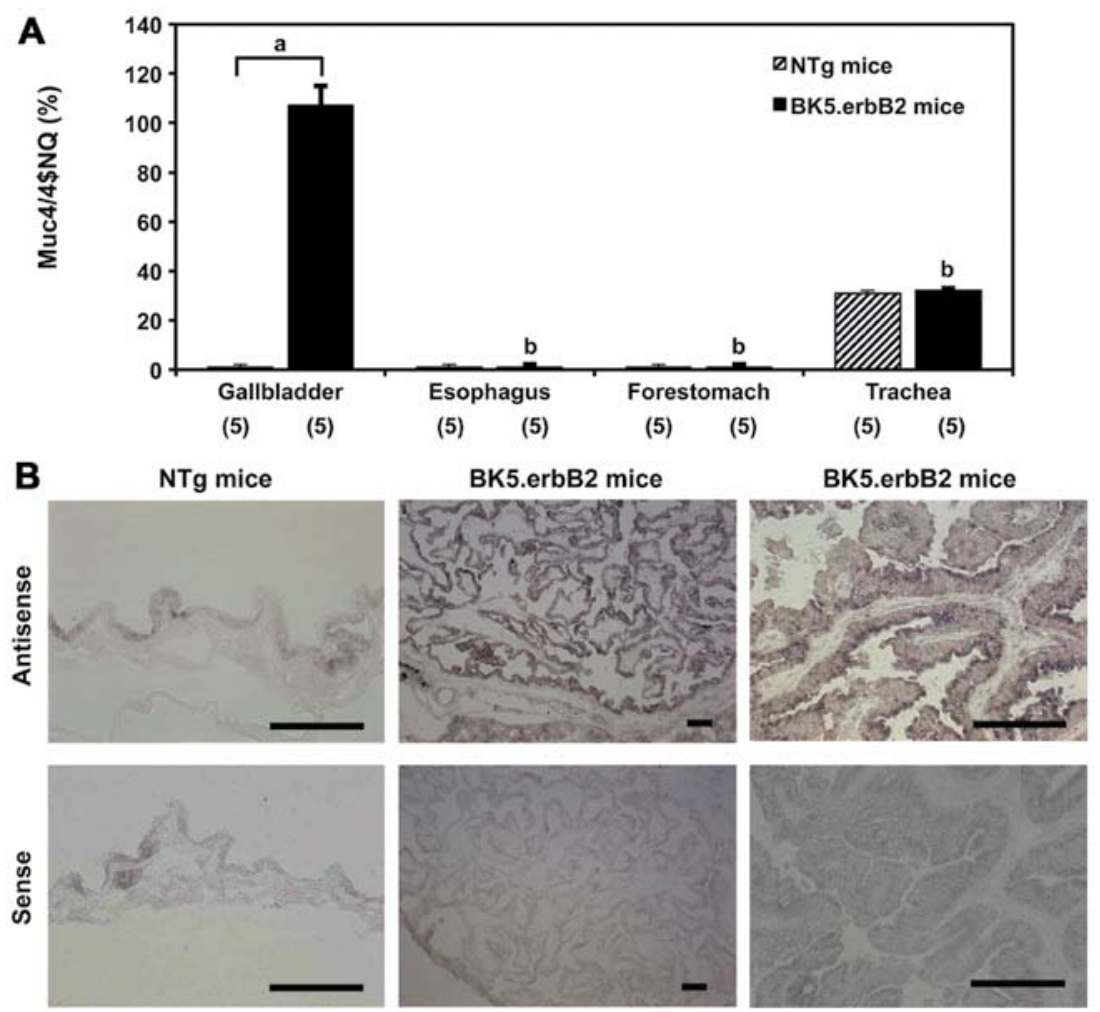

Figure 3. (A) Steady-state mRNA levels of Muc4 (ASGP2) in the gallbladder, esophagus, forestomach and trachea of non-transgenic (NTg) mice and of BK5. erbB2 transgenic mice (3 months old). The amounts of the Muc4 mRNAs were normalized to those of $r R N A$ mRNA in each specimen and then averaged. Data are given as means $\pm \mathrm{SE} .{ }^{\mathrm{a}} \mathrm{P}<0.01$, significantly different from the gallbladder of $\mathrm{NTg}$ mice; ${ }^{\mathrm{b}} \mathrm{P}<0.01$, significantly different from the gallbladder of $\mathrm{BK} 5$.erbB2 mice. (B) In situ hybridization of Muc4 mRNA in gallbladder tissue sections of NTg mice and BK5.erbB2 mice. Bars, $100 \mu \mathrm{m}$. 

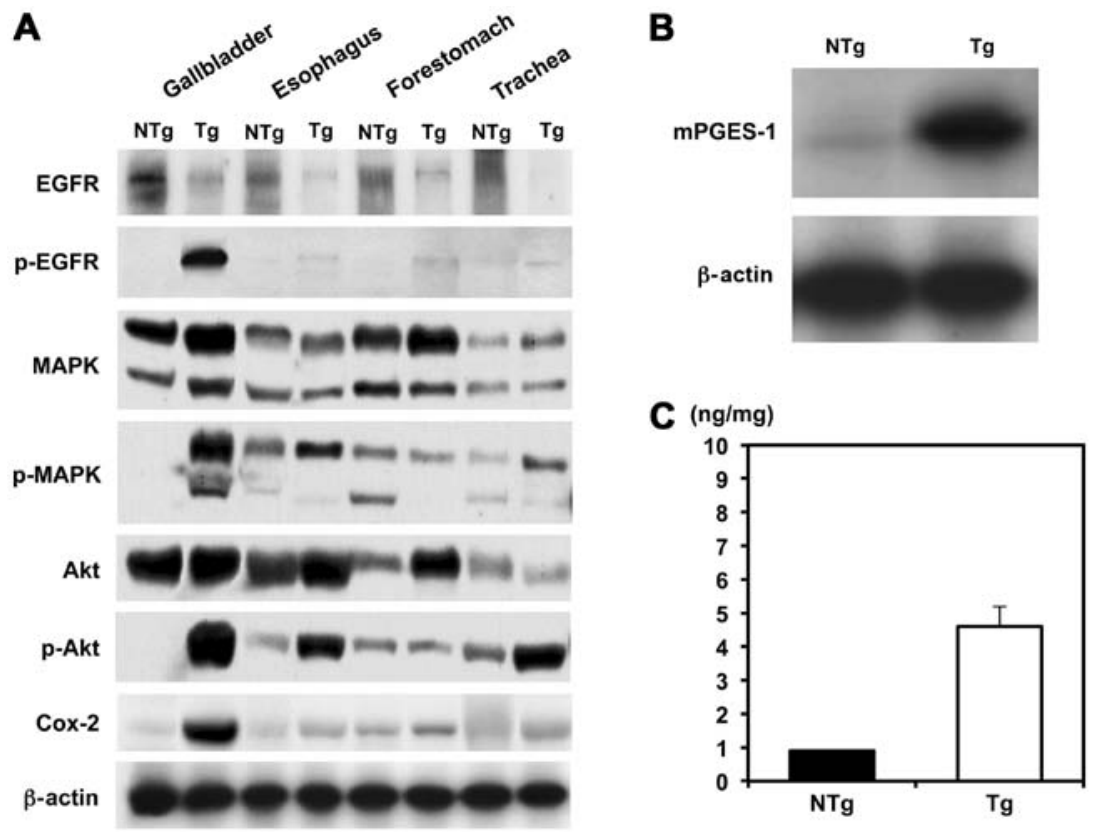

Figure 4. (A) Immunoblot analysis of MAPK, Akt and Cox-2 status in the gallbladder and other organs (in which erbB2 is overexpressed under the control of the $K 5$ promoter) of non-transgenic (NTg) mice and the corresponding organs of BK5.erbB2 transgenic mice (3 months old). The whole cell lysate was analyzed by immunoblotting with antibodies (Abs) raised against MAPK, p-MAPK, Akt, p-Akt and Cox-2. Protein was normalized to $\beta$-actin. (B) Immunoblot analysis of the mPGES-1 status in the gallbladder of NTg mice and that of BK5.erbB2 mice (3 months old). The whole cell lysate was analyzed by immunoblotting with antibody $\left(\mathrm{Ab}\right.$ ) raised against mPGES-1. Protein was normalized to $\beta$-actin. (C) Tissue concentration of $\mathrm{PGE}_{2}$ in the gallbladder of NTg mice and that of BK5. erbB2 mice (3 months old). Aliquots of tissue homogenates, which were prepared from 20 gallbladders of NTg mice and from each of 4 BK5.erbB2 mice, were assayed by a RIA for $\mathrm{PGE}_{2}$. The final results are expressed as $\mathrm{ng} \mathrm{PGE}_{2} / \mathrm{mg}$ protein.

forestomach, in each of which erbB2 is overexpressed (data not shown).

Expression status of MAPK, Akt and Cox-2 in the gallbladder and other organs of BK5.ErbB2 transgenic mice. ErbB2 regulates Cox-2 expression via the Akt and MAPK signaling pathways in human cancer cells (22-24). To clarify the mechanistic basis of gallbladder carcinogenesis in BK5.erbB2 mice, relative expression at protein levels and their phosphorylation of erbB2-associated molecules, such as MAPK, Akt and Cox-2, were investigated (Fig. 4A). In terms of erbB2-downstream molecules, phosphorylation levels of MAPK and Akt were significantly elevated in the gallbladder of BK5.erbB2 mice. Moreover, in parallel to the activation of these molecules, Cox-2 protein levels were significantly elevated in the gallbladder of BK5.erbB2 mice, and this change was associated with the overexpression of mPGES-1 (Fig. 4B) and with the overproduction of $\mathrm{PGE}_{2}$ in the gallbladder (Fig. 4C).

\section{Discussion}

Accumulating evidence suggests that constitutive expression or activation of erbB2 may be involved in the development of human biliary tract carcinomas, such as gallbladder carcinoma $(8,9)$ and cholangiocarcinoma $(20,26,27)$. This has been experimentally confirmed by the fact that constitutive overexpression of erbB2 in gallbladder epithelia of mice leads to a high incidence of adenocarcinoma (10) as well as by the results of our previous study showing that the development of gallbladder carcinoma is inhibited by treatment with selective EGFR/erbB2 tyrosine kinase inhibitors (28).
ErbB2 has been shown to lack a specific ligand that affects erbB2 signaling through the formation of heterodimers with other erbB2 family members $(29,30)$. A series of studies described by Carraway et al $(16,17)$ has implicated the involvement of Muc4 in cellular signaling. Muc4 has been shown to activate erbB2 through direct interaction with the receptor tyrosine kinase and to potentiate tumor growth in mammalian carcinoma cells $(31,32)$, and overexpression of Muc4 in the mouse mammary gland results in hyperplasia in the developing gland (16). Also, in human digestive organs, it should be noted that MUC4 is strongly expressed in adenocarcinomas of the gallbladder (18) and pancreas (33), but not in the normal gallbladder and pancreas (33). Therefore, in the present study, we investigated the hypothesis that upregulation of Muc4 and its interaction with erbB2 are involved in the process of gallbladder carcinogenesis in BK5.erbB2 mice.

In BK5.erbB2 mice, expression levels of Muc4 (ASGP2) mRNA and protein were upregulated, to a large extent, in the gallbladder carcinoma tissues, compared to the levels in gallbladders of NTg mice (Figs. 1 and 3). In immunohistochemistry, a modest degree of Muc4 protein was observed in the hyperplastic epithelia as being a precancerous lesion (data not shown). Little or no Muc4 protein was detected in the epithelia of the trachea, forestomach and esophagus of BK5.erbB2 mice, in which erbB2 is overexpressed. Hyperphosphorylated erbB2 was found in the gallbladder carcinoma tissues, but not in the other organs (Fig. 1). The results of immunoprecipitation experiments (Fig. 1) and immunofluorescent double stainings (Fig. 2) revealed a direct interaction between Muc4 and hyperphosphorylated erbB2 in the gallbladder and their co-localization in the cancerous epithelia. Collectively, it 
is likely that the expression levels of gallbladder Muc4 are increased in connection with the phosphorylation status of the erbB2 in the process of carcinogenesis, and that this molecular relationship is further enhanced in the process of cancer growth, leading to the strong expression levels of Muc4 coupled with p-erbB2. It is also likely that an interaction between Muc4 and phosphorylated erbB2 enhances erbB2-downstream signaling pathways important for the carcinogenesis. Further studies are required to elucidate the biological roles of Muc4 in carcinogenesis and/or carcinoma progression.

Upon examination of downstream signaling pathways, hyperphosphorylation of MAPK and Akt was observed in the gallbladder carcinoma tissues, suggesting that MAPK and/or $\mathrm{PI} 3 \mathrm{~K}$ signaling pathways may play a role in producing the gallbladder phenotype in BK5.erbB2 mice. Supporting the results obtained for BK5.erbB2 mice, in rat cholangiocyte transformants overexpressing activated erbB2/neu (34), an enhanced downstream signaling was observed to be p44/42 MAPK and p60 Akt. Furthermore, a selective inhibitor of erbB2 tyrosine kinase exerts a potent antitumor activity through suppressing the activation of Akt, an anti-apoptotic molecule, in erbB2-positive breast carcinoma cells, but not in erbB2-negative cells (35). The results of these in vitro experiments $(34,35)$ and those of the present in vivo experiments suggest that MAPK and Akt are erbB2-downstream molecules important for gallbladder carcinogenesis, during which the presence of Muc4 potentiates the heregulin effects on phosphorylation of erbB2, MAPK and Akt (14), and further enhances the tumor growth.

Also on downstream signaling pathways, in association with the overexpression of activated erbB2, significant upregulation of both Cox-2 and mPGES-1, a stimulus-inducible enzyme functioning downstream of Cox-2 in the $\mathrm{PGE}_{2}$-biosynthetic pathway (36), was observed in the gallbladder carcinomas of BK5.erbB2 mice (Fig. 4). A strong degree of Cox-2 expression was observed in the hyperplastic epithelia as being a precancerous lesion (data not shown). Activated erbB2 regulates Cox-2 expression via the Akt and MAPK signaling pathways in human cancer cells (23-25). It is likely that the expression levels of not only Muc4 but also Cox- 2 are increased in connection with the phosphorylation status of the erbB2 in the gallbladder. The significant overproduction of Cox-2-derived $\mathrm{PGE}_{2}$ (Fig. 4) further emphasizes the functional relationship between erbB 2 activation and Cox-2/mPGES-1 induction in the gallbladder and likely plays an important role in the carcinogenesis process. The association of Cox- 2 with erbB2/neu has also been considered important for rodent models of cholangiocarcinogenesis $(37,38)$. In rat cholangiocyte transformants overexpressing activated erbB2/neu (34), erbB2/neu overexpression coupled to Cox-2 upregulation and increased $\mathrm{PGE}_{2}$ production may act in a complementary manner to regulate telomerase expression. Collectively, overexpression of activated erbB2 coupled to Muc4, Cox-2 and mPGES-1 may contribute to tumorigenesis.

A comparison was made between gallbladder carcinoma of BK5.erbB2 mice and that of human subjects. It has been proposed that there are two primary morphological pathways for the development of human gallbladder carcinoma; one involves adenoma-carcinoma development and the other involves de novo development (39). Kawamoto et al showed that gallbladder carcinoma of BK5.erbB2 mice, all of which are well-differentiated lesions, arises via these two distinct pathways, which are reminiscent of development sequences observed in human carcinoma (22). In our previous study (19) on expression levels of MUC4 (ASGP2) and erbB2 in human carcinoma, there was a strong correlation between histological grade (well- and moderately-differentiated adenocarcinoma) and their expression levels (our unpublished data). Co-expression of MUC4 and erbB2 is present in approximately a quarter of the cases of well- and moderately-differentiated adenocarcinomas. The experiments revealed their complex formation in the carcinoma tissues (19). Moreover, overexpression of both MUC4 and erbB2 and their complex formation were associated with hyperphosphorylation of MAPK and Akt in the carcinoma tissues (19). Although clinical significance of MUC4 expression or MUC4/erbB2 complex formation is to date unknown, the relevance of BK5.erbB2 mice as a model of human gallbladder carcinoma is underscored here by the molecular and pathological similarities.

Collectively, the findings of the present study summarize that BK5.erbB2 mice develop adenocarcinoma of the gallbladder but not the other organs in which erbB2 is overexpressed. In the gallbladder, it is likely that upregulation of Muc4 in connection with the phosphorylation status of erbB2 and an interaction of Muc4 with the phosphorylated erbB2 play important biological roles in gallbladder carcinogenesis and/or cancer growth through potentiating the receptor tyrosine kinase and alteration of erbB2 downstream signaling pathways and also potentiating the erbB2-Cox-2 pathway. Transgenic approaches would be invaluable in similar situations and undoubtedly prove helpful in elucidating the biological roles of Muc4. Therapeutic options for gallbladder carcinoma are still limited. Based on the results of the present study, targeting MUC4 and erbB2 could provide a new and effective therapy for a number of patients with gallbladder carcinoma.

\section{Acknowledgements}

The authors would like to thank Dr Kaoru Kiguchi and Professor John DiGiovanni, the University of Texas, MD Anderson Cancer Center, Science Park Research Division, Smithville, Texas, USA, for their kind supply of biological tissue specimens of BK5.erbB2 transgenic mice. This study was supported by grants-in-aid (nos. 15590618, 23390318 and 24390323) for scientific research from the Ministry of Education, Science and Culture.

\section{References}

1. Henson DE, Albores-Saavedra J and Corle D: Carcinoma of the gallbladder. Histologic types, stage of disease, grade, and survival rates. Cancer 70: 1493-1497, 1992.

2. Japan VSo, Tokyo (Japan): Japanese Ministry of Health and Welfare: Statistics Assoc., 1998.

3. Cubertafond P, Gainant A and Cucchiaro G: Surgical treatment of 724 carcinomas of the gallbladder. Results of the French Surgical Association Surgery. Ann Surg 219: 275-280, 1994.

4. Rückert JC, Rückert RI, Gellert K, Hecker K and Müller JM: Surgery for carcinoma of the gallbladder. Hepatogastroenterology 43: 527-533, 1996.

5. Pandey M and Shukla VK: Diet and gallbladder cancer: a casecontrol study. Eur J Cancer Prev 11: 365-368, 2002.

6. Lowenfels AB, Lindström CG, Conway MJ and Hastings PR: Gallstones and risk of gallbladder cancer. J Natl Cancer Inst 75: 77-80, 1985. 
7. Kimura K, Ohto M, Saisho H, Unozawa T, Tsuchiya Y, Morita M, Ebara M, Matsutani S and Okuda K: Association of gallbladder carcinoma and anomalous pancreaticobiliary ductal union. Gastroenterology 89: 1258-1265, 1985.

8. Suzuki T, Takano Y, Kakita A and Okudaira M: An immunohistochemical and molecular biological study of c-erbB-2 amplification and prognostic relevance in gallbladder cancer. Pathol Res Pract 189: 283-292, 1993.

9. Yukawa M, Fujimori T, Hirayama D, Idei Y, Ajiki T, Kawai K, Sugiura R, Maeda S and Nagasako K: Expression of oncogene products and growth factors in early gallbladder cancer, advanced gallbladder cancer, and chronic cholecystitis. Hum Pathol 24: 37-40, 1993.

10. Kiguchi K, Carbajal S, Chan K, Beltrán L, Ruffino L, Shen J, Matsumoto T, Yoshimi N and DiGiovanni J: Constitutive expression of ErbB-2 in gallbladder epithelium results in development of adenocarcinoma. Cancer Res 61: 6971-6976, 2001.

11. Di Marco E, Pierce JH, Knicley CL and Di Fiore PP: Transformation of NIH 3T3 cells by overexpression of the normal coding sequence of the rat neu gene. Mol Cell Biol 10:3247-3252, 1990.

12. Kiguchi K, Bol D, Carbajal S, Beltrán L, Moats S, Chan K, Jorcano $\mathrm{J}$ and DiGiovanni J: Constitutive expression of erbB2 in epidermis of transgenic mice results in epidermal hyperproliferation and spontaneous skin tumor development. Oncogene 19 4243-4254, 2000.

13. Klapper LN, Kirschbaum MH, Sela M and Yarden Y: Biochemical and clinical implications of the ErbB/HER signaling network of growth factor receptors. Adv Cancer Res 77: 25-79, 2000.

14. Schroeder JA, Thompson MC, Gardner MM and Gendler SJ: Transgenic MUC1 interacts with epidermal growth factor receptor and correlates with mitogen-activated protein kinase activation in the mouse mammary gland. J Biol Chem 276 13057-13064, 2001.

15. Jepson S1, Komatsu M, Haq B, Arango ME, Huang D, Carraway CA and Carraway KL: Muc4/sialomucin complex, the intramembrane ErbB2 ligand, induces specific phosphorylation of ErbB2 and enhances expression of p27 $7^{\mathrm{kip}}$, but does not activate mitogen-activated kinase or protein kinaseB/Akt pathways. Oncogene 21: 7524-7532, 2002.

16. Carraway KL, Ramsauer VP, Haq B and Carothers Carraway CA Cell signaling through membrane mucins. Bioessays 25: 66-71, 2003.

17. Carraway KL III, Rossi EA, Komatsu M, Price-Schiavi SA, Huang D, Guy PM, Carvajal ME, Fregien N, Carraway CA and Carraway KL: An intramembrane modulator of the ErbB2 receptor tyrosine kinase that potentiates neuregulin signaling. J Biol Chem 274: 5263-5266, 1999.

18. Buisine MP, Devisme L, Degand P, Dieu MC, Gosselin B, Copin MC, Aubert JP and Porchet N: Developmental mucin gene expression in the gastroduodenal tract and accessory digestive glands. II. Duodenum and liver, gallbladder, and pancreas J Histochem Cytochem 48: 1667-1676, 2000.

19. Miyahara N, Shoda J, Ishige K, Kawamoto T, Ueda T, Taki R, Ohkohchi N, Hyodo I, Thomas MB, Krishnamurthy S, Carraway KL and Irimura T: MUC4 interacts with ErbB2 in human gallbladder carcinoma: potential pathobiological implications. Eur J Cancer 44: 1048-1056, 2008.

20. Shibahara H, Tamada S, Higashi M, Goto M, Batra SK, Hollingsworth MA, Imai K and Yonezawa S: MUC4 is a novel prognostic factor of intrahepatic cholangiocarcinoma-mass forming type. Hepatology 39: 220-229, 2004.

21. Braissant $\mathrm{O}$ and Wahli W: A simplified in situ hybridization protocol using non-radioactively labelled probes to detect abundant and rare mRNAs on tissue sections. Biochemica 1: 10-16, 1998.

22. Kawamoto T, Kiguchi K, Ruffino L, Dudek D, Ajiki T, Thomas M and Digiovanni J: Role of ErbB2 in the development of gallbladder cancer. Tando 19: 550-556, 2005 (In Japanese).

23. Vadlamudi R, Mandal M, Adam L, Steinbach G, Mendelsohn J, Kumar R: Regulation cyclooxygenase-2 pathway by HER 2 receptor. Oncogene 18: 305-314, 1999.
24. Qian X, LeVea CM, Freeman JK, Dougall WC and Greene MI: Heterodimerization of epidermal growth factor receptor and wild-type or kinase-deficient Neu: a mechanism of interreceptor kinase activation and transphosphorylation. Proc Natl Acad Sci USA 91: 1500-1504, 1994.

25. Murali R, Brennan PJ, Kieber-Emmons T and Greene MI Structural analysis of $185^{\mathrm{c}-\mathrm{neu}}$ and epidermal growth factor receptor tyrosine kinases: oligomerization of kinase domains. Proc Natl Acad Sci USA 93: 6252-6257, 1996.

26. Ukita $Y$, Kato $M$ and Terada T: Gene amplification and mRNA and protein overexpression of c-erbB-2 (HER-2/neu) in human intrahepatic cholangiocarcinoma as detected by fluorescence in situ hybridization, in situ hybridization, and immunohistochemistry. J Hepatol 36: 780-785, 2000.

27. Suzuki H, Isaji S, Pairojkul C and Uttaravichien T: Comparative clinicopathological study of resected intrahepatic cholangiocarcinoma in northeast Thailand and Japan. J Hepatobiliary Pancreat Surg 7: 206-211, 2000.

28. Kiguchi K, Ruffino L, Kawamoto T, Ajiki T and Digiovanni J: Chemopreventive and therapeutic efficacy of orally active tyrosine kinase inhibitors in a transgenic mouse model of gallbladder carcinoma. Clin Cancer Res 11: 5572-5580, 2005.

29. Lenferink AE, Pinkas-Kramarski R, van de Poll ML, van Vugt MJ, Klapper LN, Tzahar E, Waterman H, Sela M, van Zoelen EJ and Yarden Y: Differential endocytic routing of homo- and hetero-dimeric ErbB tyrosine kinases confers signaling superiority to receptor heterodimers. EMBO J 17: 3385-3397, 1998

30. Yarden Y and Sliwkowski MX: Untangling the ErbB signaling network. Nat Rev Mol Cell Biol 2: 127-137, 2001.

31. Komatsu M, Jepson S, Arango ME, Carothers Carraway CA and Carraway KL: Muc4/sialomucin complex, an intramembrane modulator of ErbB2/HER2/Neu, potentiates primary tumor growth and suppresses apoptosis in a xenotransplanted tumor. Oncogene 20: 461-470, 2001

32. Price-Schiavi SA, Jepson S, Li P, Arango M, Rudland PS, Yee L and Carraway KL: Rat Muc4 (sialomucin complex) reduces binding of anti-ErbB2 antibodies to tumor cell surfaces, a potential mechanism for herceptin resistance. Int J Cancer 99: 783-791, 2002.

33. Balagué C, Audié JP, Porchet $\mathrm{N}$ and Real FX: In situ hybridization shows distinct patterns of mucin gene expression in normal, benign, and malignant pancreas tissues. Gastroenterology 109: 953-964, 1995

34. Lai GH, Zhang Z, Shen XN, Ward DJ, Dewitt JL, Holt SE, Rozich RA, Hixson DC and Sirica AE: erbB-2/neu transformed rat cholangiocytes recapitulate key cellular and molecular features of human bile duct cancer. Gastroenterology 129: 2047-2057, 2005

35. Yoshida S, Naito K, Hori A, Teratani M, Koyama M, Tasaka A and Terashita Z: TAK-165, a selective inhibitor of HER2 tyrosine kinase: 2. Mechanism of antitumor activity on HER2 signal transduction pathway. Proc Am Assoc Cancer Res 43: 786, 2003.

36. Kamei D, Murakami M, Nakatani Y, Ishikawa Y, Ishii T and Kudo I: Potential role of microsomal prostaglandin E synthase-1 in tumorigenesis. J Biol Chem 278: 19396-19405, 2003.

37. Sirica AE, Lai GH, Endo K, Zhang Z and Yoon BI: Cyclooxygenase-2 and ERBB-2 in cholangiocarcinoma: potential therapeutic targets. Semin Liver Dis 22: 303-313, 2002.

38. Lai GH, Zhang Z and Sirica AE: Celecoxib acts in a cyclooxygenase-2-independent manner and in synergy with emodin to suppress rat cholangiocarcinoma growth in vitro through a mechanism involving enhanced Akt inactivation and increased activation of caspases-9 and -3. Mol Cancer Ther 2: 265-271, 2003.

39. Itoi T, Watanabe H, Ajioka Y, Oohashi Y, Takei K, Nishikura K, Nakamura Y, Horil A and Saito T: APC, K-ras codon 12 mutations and p53 gene expression in carcinoma and adenoma of the gallbladder suggest two genetic pathways in gallbladder carcinogenesis. Pathol Int 46: 333-340, 1996. 